\title{
Prescribing pattern of drugs in alcohol dependence in a tertiary care hospital
}

\author{
Upasana Dube*, Shwetha H., Shanmukananda P., Veena D. R., Ashok Kumar
}

Department of Pharmacology, Dr. B.R. Ambedkar Medical College, Kadugondanahalli, Bangalore, Karnataka, India

Received: 23 August 2017

Revised: 08 September 2017

Accepted: 21 September 2017

*Correspondence to:

Dr. Upasana Dube,

Email: upasana.dube@ gmail.com

Copyright: (C) the author(s), publisher and licensee Medip Academy. This is an openaccess article distributed under the terms of the Creative Commons Attribution NonCommercial License, which permits unrestricted noncommercial use, distribution, and reproduction in any medium, provided the original work is properly cited.

\begin{abstract}
Background: Alcohol dependence is one of the more serious public health issues in the world. It not only affects health but is also a social and economic burden. Pharmacotherapy is the main stay of treatment along with behavioural therapy for alcohol addiction. The present study was done to analyse the prescribing pattern of drugs used in alcohol dependence.

Methods: The present study is a retrospective study which was carried out in the Department of Psychiatry, Dr. B.R. Ambedkar Medical College, Bengaluru from March 2016 to August 2016. Demographic, disease and treatment details were collected and entered in the case proformas. The results were analyzed using descriptive statistics.

Results: A total of 125 prescriptions were analyzed. The most common age group was between $30-60$ years with a male predominance $(95.2 \%)$. $72 \%$ of patients were treated for alcohol dependence whereas $28 \%$ who had other co morbidities like psychosis and depression were treated appropriately. The most commonly prescribed drugs were Vitamins $(74.4 \%)$, Benzodiazepines (BZDs) $(56.8 \%)$, anticraving drugs (52\%), antipsychotics (20\%) and anti-depressant drugs (8\%). Lorazepam (45.6\%) and Baclofen (46.1\%) were the most common drugs prescribed among BZDs and Anti-craving drugs respectively. For affective disorders Olanzapine (36\%) was the commonest drug prescribed.

Conclusions: This study reveals that alcohol dependence is accompanied by other co-morbidities like psychosis, depression and anxiety. Combined therapy of Vitamins, BZDs, Anti-craving drugs along with Antipsychotic or Antidepressant drugs have been prescribed to the patients. Newer anti-craving drugs like Baclofen, Acamprosate and Naltrexone have also been prescribed.
\end{abstract}

Keywords: Alcohol dependence, Acamprosate, Baclofen, Benzodiazepines, Naltrexone

\section{INTRODUCTION}

The menace of alcohol consumption has been on a rise globally since the last few years. India has shown a rise of as high as $106.7 \%$ in the last 10 years.

According to WHO about $30 \%$ of Indians consume alcohol, out of which around $50 \%$ are hazardous drinkers and the mean age has fallen from 28 years to 17 years unfortunately. ${ }^{1}$

Globally alcohol consumption results in 3.3 million deaths each year (WHO Global status report on alcohol and health). ${ }^{1}$ In fact, it is the $3^{\text {rd }}$ largest risk factor for disease and disability in the world. In 2010, 5.5\% of total DALYs (Disability Adjusted Life Years) were lost worldwide (Lancet's global disease burden study). ${ }^{2}$

Various studies suggest that the younger drinkers, with family history of drinking and alcoholism are the vulnerable group to develop addiction. ${ }^{3}$

Pharmacotherapy along with behavioural therapy plays an important role in preventing alcohol addiction. Advances in neurobiology and their associated neurotransmitter systems in development of alcohol dependence are also the potential targets for pharmacological approaches. ${ }^{4}$ 
Our study focuses on analyzing the prescribing pattern of drugs in alcohol dependent patients.

\section{METHODS}

After obtaining permission from the Institutional Ethics Committee, a retrospective, cross sectional study was conducted in Department of Psychiatry, DR. B.R. Ambedkar Medical College for a period of 6 months from March 2016 to August 2016.

A retrospective study also called as historic cohort study, is a longitudinal cohort study used in medical and psychological research. The data is collected from existing records and can immediately be analysed.

Retrospective studies exhibit some advantages over prospective studies like they are conducted on a small scale, they require less time to complete, they are generally less expensive because resources are mainly devoted to collecting data.

\section{Inclusion criteria}

All patients above the age of 18 years who were diagnosed with alcohol dependence per the DSM-4 TR (Diagnostic and Statistical Manual of Mental Disorders) criteria were included irrespective of gender.

\section{Exclusion criteria}

Patients with other substance abuse along with alcohol were not included.

As the data collected was retrospective no patient interaction or follow up was required. Data from the existing files in the department were studied and sorted into case recording proformas and then analysed.

The important details noted were patients ID, gender, diagnosis i.e. alcohol dependence with any other psychiatric co-morbidities and drugs prescribed.

The results were analysed using descriptive statistics and were depicted with the help of pie and bar charts.

\section{RESULTS}

Prescriptions give an insight into the nature of health care delivery system in Drug Utilization Research. ${ }^{5}$

Psychosocial treatment has been effective in treatment of Alcohol dependence, however nearly 20\% showed relapses, therefore necessitating use of pharmacotherapy. ${ }^{6}$

A total of 125 prescriptions of patients suffering from alcohol dependence were analyzed. Out of which 119 patients were male $(95.2 \%)$ and 6 were female $(4.8 \%)$
(Figure 1), this indicates that the burden of alcohol dependence is more on the male gender.

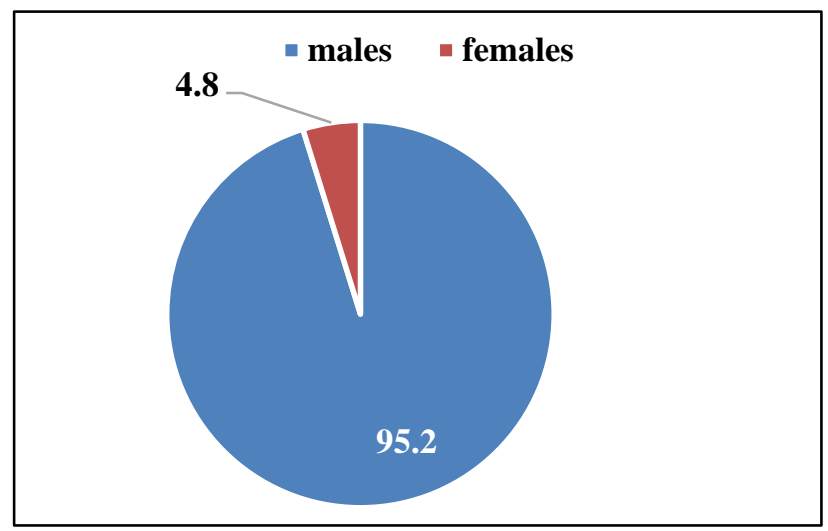

\section{Figure 1: Gender distribution in alcohol dependent patients.}

$72 \%$ patients were treated for only alcohol dependence. $20 \%$ patients were also treated with antipsychotic drugs and $8 \%$ of the patients were prescribed with antidepressant drugs (Figure 2). The common psychiatric co-morbidities seen along with alcohol dependence were psychosis and depression along with various anxiety disorders as well.

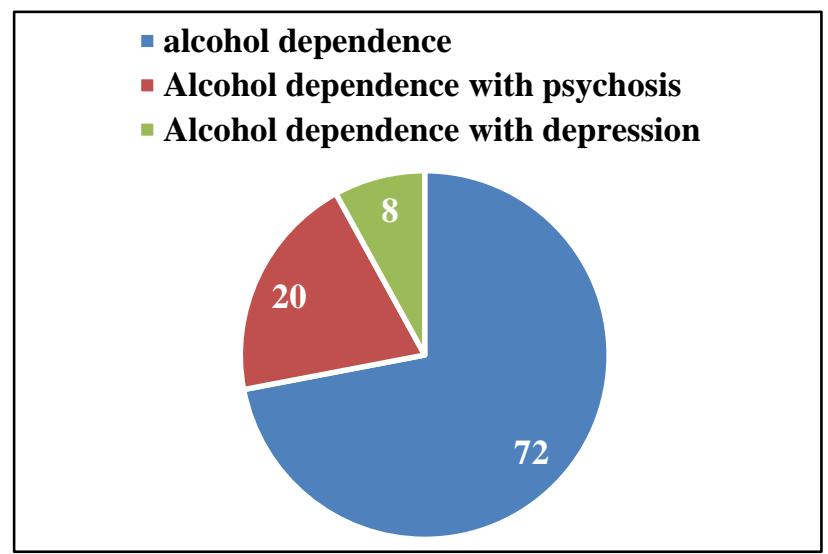

Figure 2: Alcohol dependence with psychiatric co-morbidities.

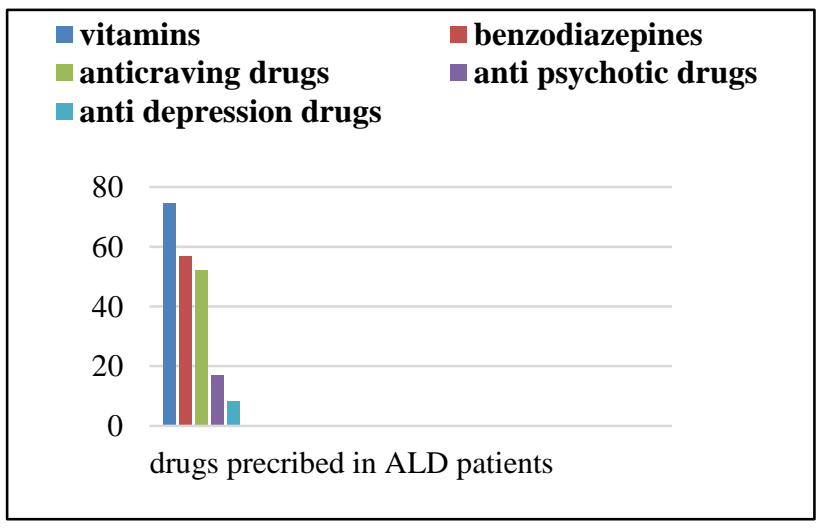

Figure 3: Prescribing pattern of drugs in alcohol dependence. 
The most commonly prescribed drugs were Vitamins (74.4\%), BZDs (56.8\%), anti-craving drugs (52\%), antipsychotics (20\%) and anti-depressant drugs (8\%) (Figure 3).

Among the BZDs, Lorazepam (80.2\%) was the most common drug prescribed followed by Chlordiazepoxide (16.9\%) (Figure 4). Other drugs prescribed were Diazepam and $\mathrm{Z}$ compounds.

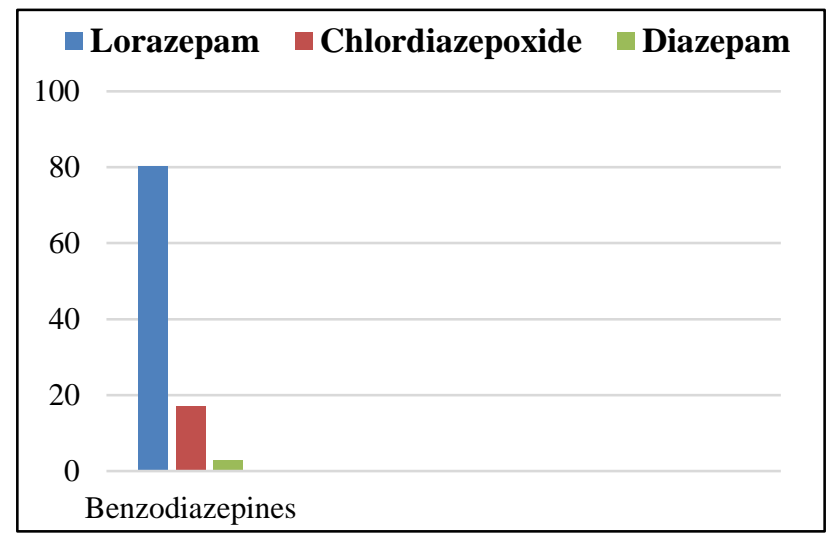

Figure 4: Prescribing patterns of benzodiazepines for withdrawal symptoms in alcohol dependence.

For long term relapse prevention, anti-craving drugs like Baclofen $(46.1 \%)$, Acamprosate $(30.7 \%)$ and Naltrexone $(23 \%)$ were prescribed (Figure 5$)$.

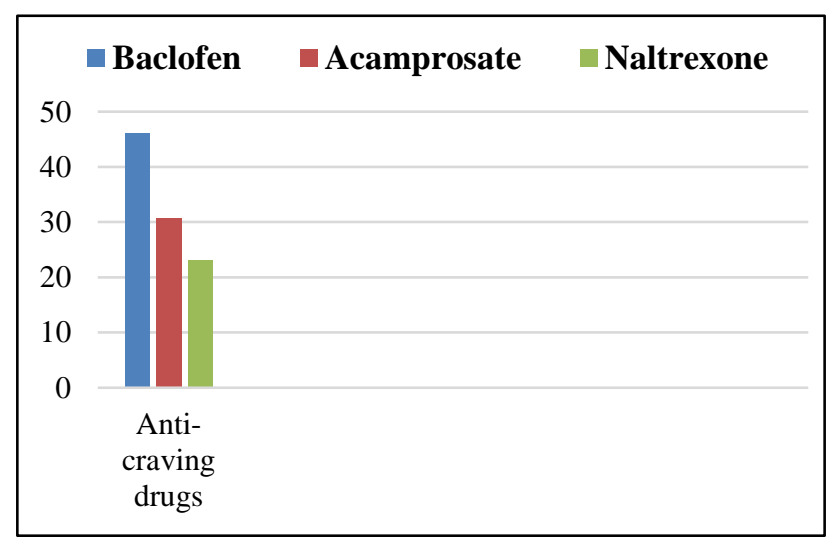

Figure 5: Prescribing patterns of anti-craving drugs in alcohol dependence.

Naltrexone, an opioid antagonist, blocks the effect of endogenous opioids which tend to increase after alcohol consumption.

Acamprosate is a derivative of the essential amino acid taurine and is structurally similar to GABA. It enhances GABAergic neurotransmission, which is decreased in alcohol dependent patients. It also decreases the action of glutamate receptors, acts on calcium channels and reduces central nervous system hyper-excitability. All these actions make it effective for better abstinence from alcohol.
Baclofen is a GABA receptor agonist, it blocks the synaptic reflexes by acting as an inhibitory neurotransmitter.

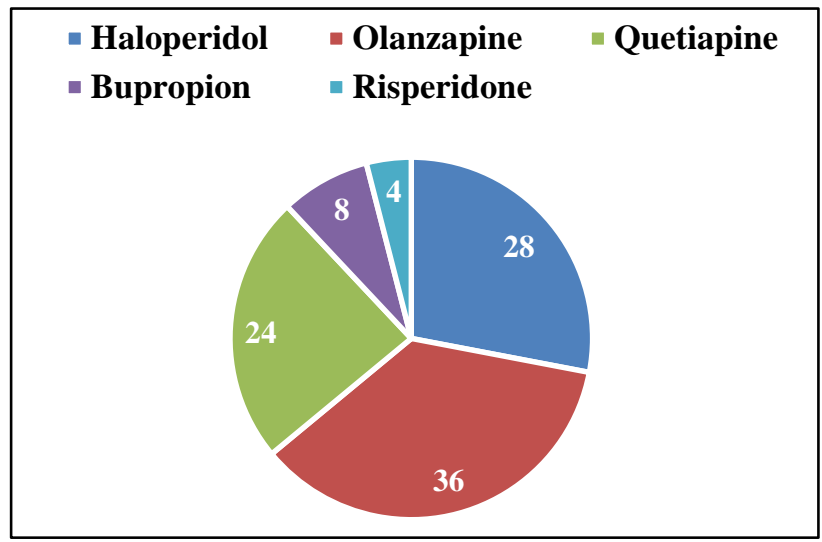

Figure 6: Prescribing patterns of drugs for psychosis in alcohol dependent patients.

For associated affective disorders like psychosis, Olanzapine (36\%), Haloperidol (30\%), Quetiapine (24\%) and Risperidone ( $8 \%$ ) were the common drugs prescribed (figure 6) followed by Escitalopram (30\%), Nortriptyline (30\%), Amitriptyline (20\%) and Sertraline (20\%) were the most commonly prescribed drugs for Depression (Figure 7).

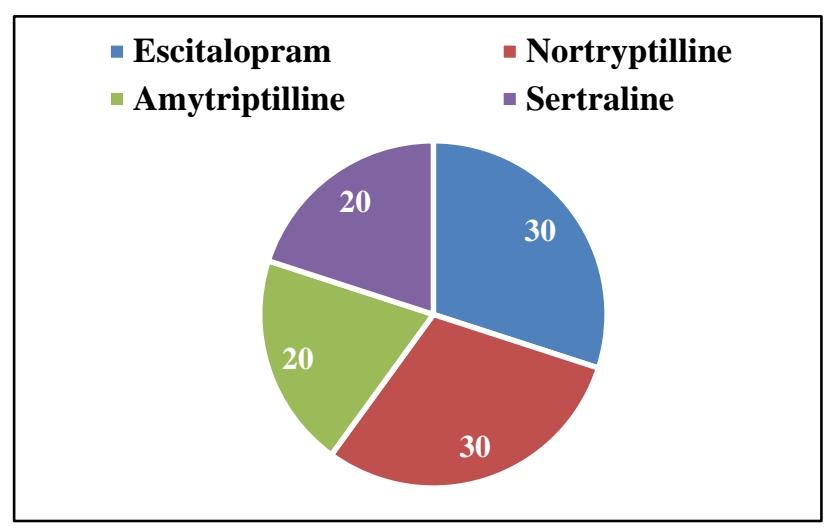

Figure 7: Prescribing patterns of drugs for depression in alcohol dependent patients.

\section{DISCUSSION}

Various studies like "Addressing alcohol addiction: lessons from a hospital based audit" by Prabhat Chand, CK Naveen et $\mathrm{al}^{7}$ explained the need of long term pharmacological interventions with various behavioral therapies as the key to decrease the alcohol addiction burden in the society.

In our study multivitamins were prescribed to all patients with alcohol dependence. In a study done by Bhanu Prakash $\mathrm{k}$ et al, multivitamins were the $2^{\text {nd }}$ most common drugs prescribed in alcoholic liver disease. ${ }^{8}$ This indicates 
that multivitamins are necessary to treat nutritional deficiencies commonly suffered by alcoholic patients.

For decreasing the withdrawaI symptoms, BZDs like Lorazepam, Chlordiazepoxide and Diazepam were prescribed in our study which was in line with the studies done by Hoey LL et al, where Lorazepam and Chlordiazepoxide are the common BZDs being prescribed. ${ }^{9}$ Hence, BZDs are effective in treatment of withdrawal symptoms in alcohol dependent patients.

In our study Baclofen, Acamprosate and Naltrexone were the most commonly prescribed anti-craving drugs, emulating the Study conducted by Atul A et al, and Julie Dupouy et al, which provided consistent evidence of use of Acamprosate, Naltrexone and Baclofen as anti-craving drugs. ${ }^{10,11}$

This pattern of prescribing anti-craving drugs in alcohol dependence is similar to that approved by the US FDA.

Previous studies showed use of Disulfiram for alcohol craving. ${ }^{12}$ This change in the prescribing pattern in the anticraving drugs is because of the better and clearer understanding of neurobiology of alcohol deaddiction techniques. $^{7}$ There is a decreased trend of using Disulfiram, probably because of high requirement of patient's willingness to stop alcohol completely and its associated adverse drug reactions.

In our study, anti-craving drugs are prescribed as monotherapy where as in a study by Lohit $\mathrm{K}$ et al, they were prescribed as combination therapy. ${ }^{13}$ Due to the complex neurobiology regarding de-addiction process, treatment with combination therapy of various anticraving agents are advocated in patients not responding to monotherapy.

Alcohol dependence is associated with various psychiatric comorbidities. An integrated approach is essential to address this issue as seen in the study be Ismene, et al. ${ }^{14}$ In our study too other co-existent affective disorders were treated with antipsychotics and antidepressants.

\section{CONCLUSION}

Alcohol dependence is seen to co-exist with various other co-morbidities like psychosis, anxiety and depression. The use of BZDs along with multivitamins and anti-craving drugs is the main stay of treatment for these alcohol dependent patients. Newer anti-craving agents like Baclofen, Acamprosate and Naltrexone have been prescribed in our study.

Funding: No funding sources Conflict of interest: None declared

Ethical approval: The study was approved by the Institutional Ethics Committee

\section{REFERENCES}

1. World Health Organization, World Health Organization. Management of Substance Abuse Unit. Global status report on alcohol and health. World Health Organization; 2014.

2. Lancet's Global Disease Burden Study 2010. thelancet.com

3. Gururaj G, Murthy P, Girish N, Benegal V. Alcohol related harm: Implications for public health and policy in India. Bangalore: NIMHANS. 2011.

4. Desouza A. Pharmacotherapy of alcohol dependence: A state of art review. Mens Sana Monogr. 2010 JanDec;8(1):69-82.

5. Introduction to Drug Utilization Research, Geneva WHO, 2003.

6. Johnson BA, Ruiz P, Lippincott, William and Wilkins. Handbook of clinical alcohol treatment; 2003.

7. Chand P, Naveen CK, Murthy P, Isaac M. Addressing alcohol addiction: lessons from a hospital based audit. The Indian journal of medical research. 2013 Feb;137(2):394.

8. Bhanu PK. Prescribing patterns of drugs in patients with alcoholic liver disease in a tertiary care hospital. National journal of Physiology, Pharmacy and Pharmacology. 2017:7(5).

9. Hoey LL, Nahum A et al. A prospective evaluation of Benzodiazepine guidelines in management of patients hospitalized for alcohol withdrawal. PMID. 1994:579585.

10. Ambekar A, Kattimani S. Anti-Craving Medications in the Treatment of Alcoholism.

11. Dupouy J, Fournier JP, Jouanjus É, Palmaro A, Poutrain JC, Oustric S, et al. Baclofen for alcohol dependence in France: incidence of treated patients and prescription patterns- a cohort study. European Neuropsychopharmacology. 2014 Feb 28;24(2):1929.

12. Babu RS, Sengupta S. A study of problem drinkers in a general hospital. Indian J of psychiatry. 1997;39:137.

13. Lohit K. Factors affecting adherence to anti-craving medications. J Pharmacol Phamacother. 2016;7(2):729.

14. Ismene LP, Gerardo G, Robert R. Comorbidity of Alcoholism and Psychiatric Disorders. NIAAA.

Cite this article as: Dube $\mathrm{U}$, Shwetha $\mathrm{H}$, Shanmukananda P, Veena DR, Kumar A. Prescribing pattern of drugs in alcohol dependence in a tertiary care hospital. Int J Basic Clin Pharmacol 2017;6:2621-4. 